\title{
Refined broad-scale sub-glacial morphology of Aurora Subglacial Basin, East Antarctica derived by an ice-dynamics-based interpolation scheme
}

\author{
J. L. Roberts ${ }^{1,2}$, R. C. Warner ${ }^{1,2}$, D. Young ${ }^{3}$, A. Wright ${ }^{4}$, T. D. van Ommen ${ }^{1,2}$, D. D. Blankenship ${ }^{3}$, M. Siegert ${ }^{4}$, \\ N. W. Young ${ }^{1,2}$, I. E. Tabacco ${ }^{5}$, A. Forieri ${ }^{5}$, A. Passerini ${ }^{6}$, A. Zirizzotti $^{6}$, and M. Frezzotti ${ }^{7}$ \\ ${ }^{1}$ Department of Sustainability, Environment, Water, Population and Communities, Australian Antarctic Division, \\ Hobart, Tasmania, Australia \\ ${ }^{2}$ Antarctic Climate and Ecosystems Cooperative Research Centre, Private Bag 80, Hobart, Tasmania 7001, Australia \\ ${ }^{3}$ Institute of Geophysics, Jackson School of Geosciences, University of Texas at Austin, Austin, Texas, USA \\ ${ }^{4}$ School of GeoSciences, University of Edinburgh Edinburgh, Scotland, UK \\ ${ }^{5}$ Geofisica, Universita di Milano, Milan, Italy \\ ${ }^{6}$ Istituto Nazionale Geofisica e Vulcanologia, Rome, Italy \\ ${ }^{7}$ Agenzia nazionale per le nuove tecnologie, l'energia e lo sviluppo economico sostenibile, Rome, Italy
}

Received: 27 January 2011 - Published in The Cryosphere Discuss.: 17 February 2011

Revised: 27 June 2011 - Accepted: 1 July 2011 - Published: 13 July 2011

\begin{abstract}
Ice thickness data over much of East Antarctica are sparse and irregularly distributed. This poses difficulties for reconstructing the homogeneous coverage needed to properly assess underlying sub-glacial morphology and fundamental geometric constraints on sea level rise. Here we introduce a new physically-based ice thickness interpolation scheme and apply this to existing ice thickness data in the Aurora Subglacial Basin region. The skill and robustness of the new reconstruction is demonstrated by comparison with new data from the ICECAP project. The interpolated morphology shows an extensive marine-based ice sheet, with considerably more area below sea-level than shown by prior studies. It also shows deep features connecting the coastal grounding zone with the deepest regions in the interior. This has implications for ice sheet response to a warming ocean and underscores the importance of obtaining additional high resolution data in these marginal zones for modelling ice sheet evolution.
\end{abstract}

\section{Introduction}

The response of the Antarctic and Greenland ice sheets to climate change is an important issue as each has the potential to make substantial, rapid and prolonged contributions

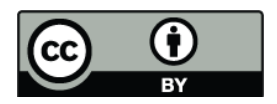

Correspondence to: J. L. Roberts

(jason.roberts@aad.gov.au) to sea level rise. Recent advances in satellite based monitoring of these ice sheets are providing an increasingly accurate record of changes to their mass (Pritchard et al., 2009; Velicogna, 2009). In Greenland and West Antarctica much of the recently observed mass loss is due to increases in the discharge of certain key glaciers rather than changes in the rate of surface melt (Allison et al., 2009).

The dynamic response of a marine ice sheet (substantial area of the bedrock below sea-level) near its coastal margins is strongly influenced by the interaction between the ocean and the floating ice (Weertman, 1974). The processes that control the migration of the grounding line are not well understood. Under certain geometrical configurations, where bedrock is below sea level and deepens inland, it is thought these processes may lead to an instability resulting in accelerating flow, rapid retreat of the grounding line and sustained sea level rise (Mercer, 1978; Thomas, 1979).

The first step to understanding the ultimate impact of the cryosphere on sea level requires delineating the first-order geometry of the major ice sheets, including volume and susceptibilities to marine ice sheet instabilities. Such geometry is either largely or wholly unknown for large regions in East Antarctica (Siegert, 2008), especially the bed topography data in the Aurora Subglacial Basin region of East Antarctica. The existing ice thickness measurements for this region are highly non-uniformly distributed (see Fig. 1) with large spatial gaps.

Published by Copernicus Publications on behalf of the European Geosciences Union. 

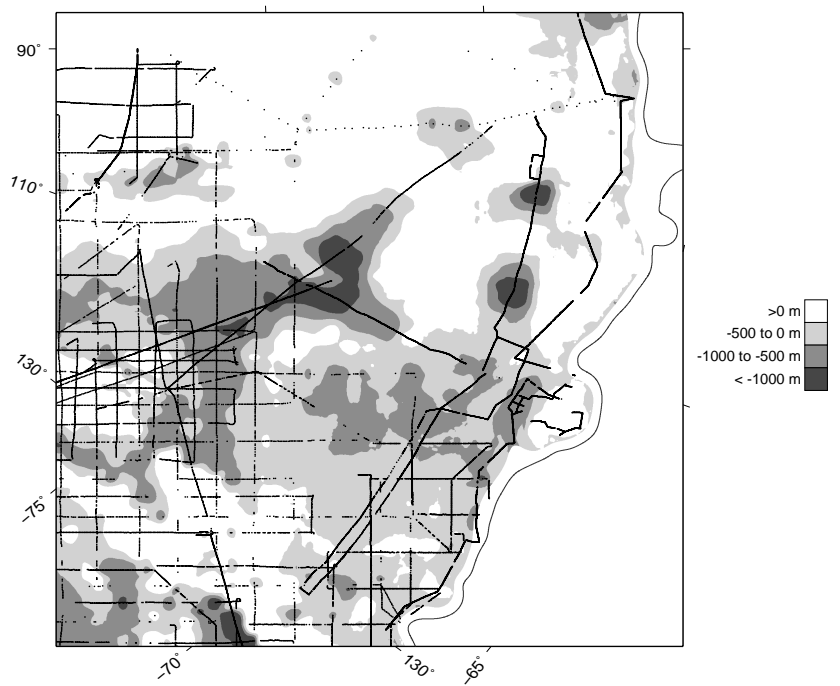

Fig. 1. BEDMAP ice sheet bed elevation, the location of prior datasets is also shown. The horizontal reference coordinate system used herein is a polar stereographic projection with $71^{\circ} \mathrm{S}$ as the latitude of true scale and $0^{\circ} \mathrm{E}$ as the central meridian. The vertical coordinate is relative to the GGM01C geoid.

Here we present a scheme for interpolating ice sheet thickness which is significantly less sensitive to the absence or exclusion of data than traditional inverse distance type schemes (i.e "robust" to data sparsity). This new scheme incorporates large scale ice flow properties based on Warner and Budd (2000) and we apply this to the Aurora Subglacial Basin and surrounding region by combining historical data-sets (Lythe et al., 2001; Young et al., 1989a,b; Urbini et al., 2010) with a $1 \mathrm{~km}$ ice sheet surface digital elevation model (DEM) (Bamber et al., 2009). The skill of the new interpolation scheme is assessed by comparison to the interim ice thickness measurements from the first season of the ICECAP project (Young et al., 2011). The ICECAP instrument suite is based on SOAR equipment (Blankenship et al., 2001), and uses the HiCARS high bandwidth ice penetrating radar (Peters et al., 2005), geolocated by GPS. Derived ice thickness data, assuming a propagation velocity of $1.69 \times 10^{8} \mathrm{~ms}^{-1}$ and no firn correction, have an RMSE of $47 \mathrm{~m}$ in steep topography (Holt et al., 2006) with a ice thickness precision within $6 \mathrm{~m}$.

\section{Ice dynamics based interpolation}

The ice sheet surface elevation and ice dynamics provide additional constraints on the ice sheet thickness, which we use in a physically-based interpolation scheme to better resolve the basal elevations.

The historical ice thickness data (Fig. 1 displays the location of the data superimposed on a schematic of the BEDMAP dataset from Lythe et al., 2001) were first mapped

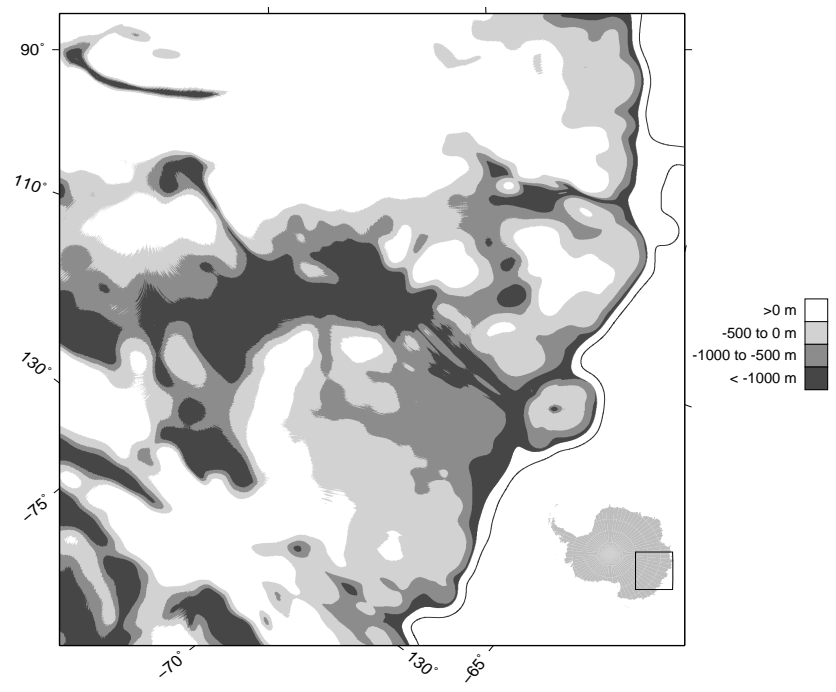

Fig. 2. Unconstrained inferred ice sheet basal elevation based on a constant $\kappa=1$.

onto a $1 \mathrm{~km} \times 1 \mathrm{~km}$ grid using the average of multiple observations on any grid cell. These mapped observations are interpolated here using a scheme based on the thickness modeling of Warner and Budd (2000). That model uses the shallow-ice approximation for ice flow and relies on the availability of the magnitude of ice flux (cubic metres per year between the surface and bed per metre width normal to the flow direction, in units of $\left.\mathrm{m}^{2} \mathrm{yr}^{-1}\right), F(x, y)$, and gradient of the surface elevation, $s(x, y)$, (with the gradient calculated via central differencing of the smoothed (see Sect. 2.1) $1 \mathrm{~km} \times 1 \mathrm{~km}$ surface elevations) at all spatial locations $(x, y)$ where the ice thickness, $D(x, y)$, is required, namely

$D(x, y)=\kappa\left(\frac{c_{0} F(x, y)}{|\nabla s(x, y)|^{3}}\right)^{\frac{1}{5}}=\kappa t(x, y)$

where Warner and Budd (2000) suggest a value of $c_{0}=$ $10^{5} \mathrm{~m}^{3} \mathrm{yr}$, corresponding to an ice flow rate constant in the Glen cubic $(n=3)$ flow relation (with the exponents 3 and $\frac{1}{5}$ in Eq. (1) resulting from $n$ and $\frac{1}{n+2}$, respectively), yielding $t(x, y)$ as a pseudo ice thickness (in $\mathrm{m}$ ), with magnitude approximately that of the local ice thickness. We have introduced the dimensionless factor $\kappa$, with magnitude of order unity, as a locally tunable parameter to compensate for local deviations from the modelling of Warner and Budd (2000).

The interpolation scheme of Warner and Budd (2000) is obtained by setting $\kappa=1$ everywhere. Using this constant $\kappa$ and no additional constraining ice thickness data, Eq. (1) reproduces the major features of the topography (Fig. 2). But it produces over-deepening near ridges, Lake Vostok and in ice streams which is the result of the small surface elevation gradients, $\nabla s(x, y)$, in these regions (Figs. 3 and b), and the inapplicability of the simple shallow-ice approximation 

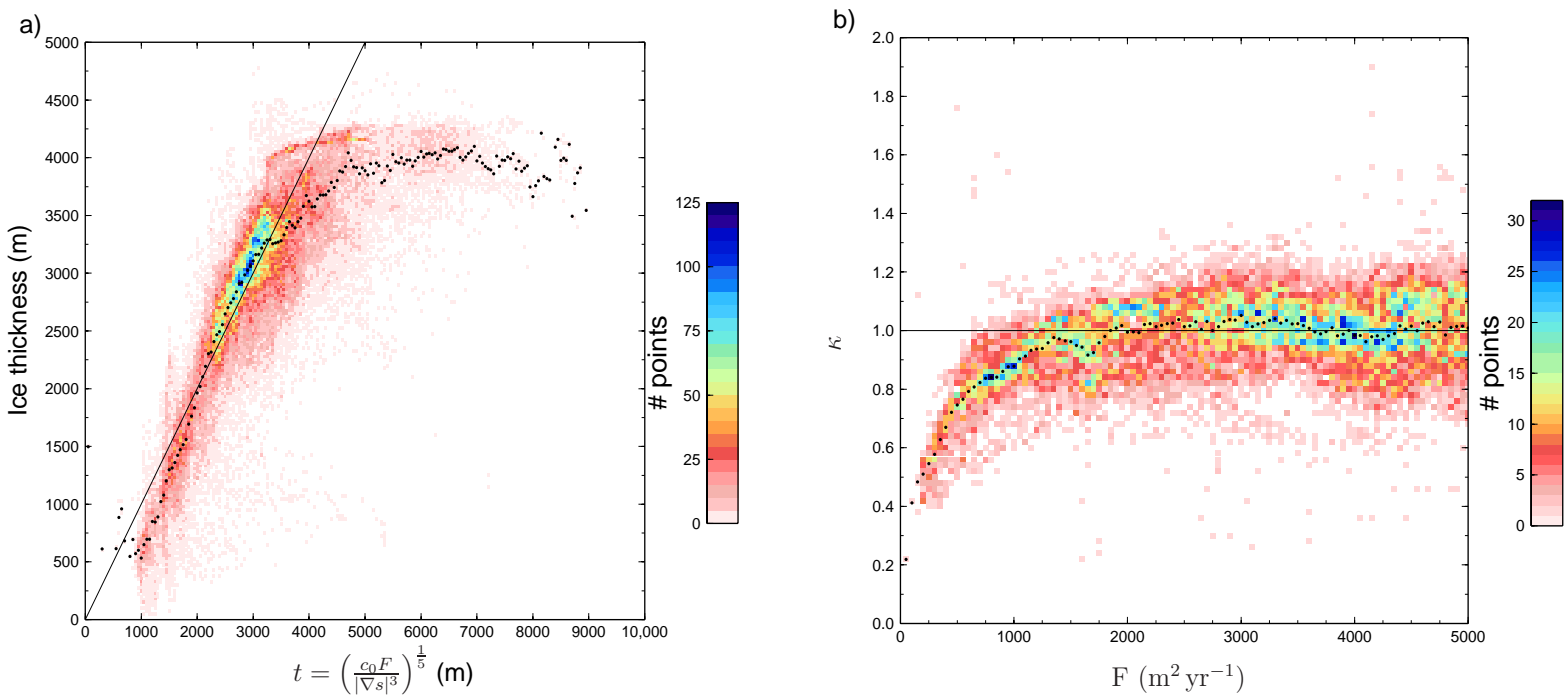

Fig. 3. (a) Basin wide characteristics from the ICECAP data and the ice dynamics based interpolation. Binned distribution of measured ice thickness and pseudo thickness $(t)$. Also shown are medians of ice thickness $(D)$ of the binned distribution (dots) and the line of slope 1 corresponding to $c_{0}=10^{5} \mathrm{~m}^{3} \mathrm{yr}$. Note the breakaway from constant slope at high pseudo thickness. This corresponds to ridges, saddles, Lake Vostok and ice streams. (b) Binned distribution of $\kappa$ at low ice fluxes. Also shown are medians of $\kappa$ of the binned distribution (dots) and the constant line $\kappa=1.0$.

around summits, which would result in a transition from the cubic Glen flow relation $(n=3)$ in Eq. (1) to a linear relation $(n=1)$ (Pettit and Waddington, 2003) and a different $c_{0}$.

To overcome these limitations, here we introduce $\kappa$ and allow it to vary over the spatial domain of interest in order to assimilate the ice thickness observations. From the view point of dynamics this variability in $\kappa$ allows for local variations in ice flow conditions including possible departures from the shallow-ice approximation. Therefore Eq. (1) offers the prospect of a method for interpolating ice thicknesses as $t(x, y)$ is known everywhere (see Sect. 2.1) and $\kappa$ can be estimated from local data (see Sect. 2.2).

\subsection{Ice fluxes}

The ice fluxes were obtained using a Lagrangian balance flux code that assumes the ice sheet is in local equilibrium so that the accumulation rate and the downstream advection are in balance. The local accumulation surrounding the origin of each streamline is advected downstream as a point mass, in contrast to the flow line method of Testut et al. (2003) which considered the surface between two distinct flow lines. The accuracy of the streamline tracing in the Lagrangian frame is ensured via a multi-step predictor-corrector algorithm with $25 \mathrm{~m}$ steps for the streamline integration. Individual streamlines are mapped back to an Eulerian grid where the flux is calculated taking into account the Eulerian cell width normal to the local flow direction. The streamline integration is preformed in the Lagrangian frame with sub-metre precision and mapped back to a $1 \mathrm{~km} \times 1 \mathrm{~km}$ Eulerian grid, therefore each cell in the Eulerian grid can contain multiple, distinct streamlines. Additional accuracy is obtained by oversampling the Lagrangian streamlines, in particular each Eulerian cell is the origin for 16 streamlines, arranged in a regular $4 \times 4$ spatial grid and each advecting one-sixteenth of the accumulation from the Eulerian cell. Here the flow is assumed to be in the direction of steepest descent, evaluated on a broad scale, consistent with the shallow-ice approximation. The use of a Lagrangian framework removes possible grid orientation dependency (Le Brocq et al., 2006) associated with numerical diffusion. Surface topography is from Bamber et al. (2009) with the following modifications: Gaussian smoothing with a spatial invariant radial filtering with a half maximum radius of $23.5 \mathrm{~km}$, pit filling and plateau removal (Soille et al., 2003).

The accumulation field from van de Berg et al. (2006) was used to drive the balance flux code. Variations in the calculated mass flux for other accumulation fields should have only a minimal influence on the calculated ice thickness, due to both the 1/5 exponent in Eq. (1) and the relative local variability assimilated into the flow parameter $(\kappa)$.

\subsection{Interpolation methods}

In the following it will be seen that the dynamical approach gives superior interpolation skill over the vast majority of the ice sheet, but cannot be applied across the full range of surface gradients and ice fluxes. In the regions where the dynamical method is not applicable it is replaced by a more 
traditional inverse-distance-cube (IDC) interpolation method (see for example Lythe et al., 2001).

Inspection of the relationship between measured ice thickness $D$ and the pseudo thickness $t$ (Fig. 3) shows a clustering of values along a line of constant slope (corresponding to $c_{0}$ ) over much of the range of $t$. The distribution diverges strongly at both high and low $t$ due to low slope and fluxes, respectively. This corresponds, in general, to regions near domes, ridges and saddles where the shallow-ice approximation is not appropriate, and a linear flow relation $(n=1)$ in Eq. (1) (Pettit and Waddington, 2003) would be more appropriate. These regions are excluded from the dynamical interpolation by enforcing the limits $t(x, y) \leq 6000 \mathrm{~m}$ and $F(x, y)>600 \mathrm{~m}^{2} \mathrm{yr}^{-1}$.

Together these criteria exclude only $<3.5 \%$ of the ice sheet in this region. As noted above, for these excluded areas the interpolation method defaults to IDC (see Sect. 2.2). Note that the combination of the above two limits with Eq. (1) imposes a lower bound on the surface gradient of $|\nabla s(x, y)| \geq$ $2.0 \times 10^{-4}$.

In the dynamically motivated approach two different interpolation methods for $\kappa$ are used selectively to produce the gridded ice thickness and finally the ice sheet basal elevation, while a third (IDC) method is employed where the dynamical interpolation cannot be applied. The basic idea is to interpolate based on similarity of the pseudo thickness where appropriate (see limitations in Sect. 2), as $\kappa$ is relatively constant with this factor. The three methods trade-off higher skill (see Sect. 3) with applicability that is restricted by the distribution of the data. The final interpolation scheme combines these three methods depending on the availability of data and the applicability of the methods, resulting in a single estimate of the ice thickness and ice sheet basal elevation. Subject to the constraints given above, the streamline interpolation method (Sect. 2.2.1) is the preferred method, followed by the pseudo thickness weighted method (Sect. 2.2.2) and lastly, an IDC method (Sect. 2.2.3) filling in the remaining data gaps. Pseudo code for the algorithm combining these three methods into the complete interpolation scheme, named TELVIS (Thickness Estimation by a Lagrangian Validated Interpolation Scheme) is given in Appendix A, and the individual methods are detailed below.

\subsubsection{Streamline interpolation}

The relationship between ice thickness and pseudo thickness along streamlines is determined mainly by the flow along the streamline. This is advantageous for the interpolation of thickness. Where multiple observations along a streamline exist, this is the preferred interpolation method. Where there is more than one observed ice thickness on a streamline, $\kappa(p)$ at grid cell $p$ along the streamline can be calculated from

$\kappa(p)=\frac{\sum_{i} \kappa(i) /\left(\left|t_{i}-t_{p}\right|+\epsilon\right)}{\sum_{i} 1 /\left(\left|t_{i}-t_{p}\right|+\epsilon\right)}$ where $\epsilon$ is a small constant to avoid division by zero. The summations range over all streamlines involving $p$ and using the nearest upstream and downstream observational cells for each streamline, and the inverse weighting using the pseudo thickness field, putting an emphasis on similarity of that quantity, rather then on proximity. The values of $\kappa(i)$ are known for all $i$, since at the observational cells $(i)$ we know both the ice thickness (measured) and pseudo thickness. Note that typically there are several upstream cells and one downstream cell, reflecting the convergence of flow into ice-streams resulting in multiple streamlines passing through a Eulerian grid cell.

\subsubsection{Pseudo thickness weighted}

This method also derives a locally based $\kappa$ using neighbouring data from both observations and the streamline method (Sect. 2.2.1), once again weighted to favour those points with similar pseudo thickness. It takes the two nearest points in each octant with the caveat that the selected points must lie on different streamlines in each octant.

A local $\kappa(p)$ at grid cell $p$ is then calculated from

$\kappa(p)=\frac{\sum_{j} \kappa(j) /\left(\left|t_{j}-t_{p}\right|^{0.5}+\epsilon\right)}{\sum_{j} 1 /\left(\left|t_{j}-t_{p}\right|^{0.5}+\epsilon\right)}$

The skill of this method varies only weakly with the exponent, with the empirically chosen value of 0.5 being a weak optimum selected to minimise the bias of the calculated ice thicknesses compared to the observed ice thicknesses. Note that the summation indices of Eqs. (2 and 3) differ, in the former being over all streamlines passing through the grid cell, while in the latter involving 16 cells, two from each octant.

\subsubsection{Inverse Distance Cube}

For all remaining grid points $p$, an IDC method is used,

$D(p)=\frac{\sum_{j} D(j) / R_{j}^{3}}{\sum_{j} 1 / R_{j}^{3}}$

where the summation index ranges over the nearest two observational cells in each octant, and $R_{j}$ is the distance between the cells $p$ and $j$. To simplify further processing steps, this thickness is then converted back to a local flow parameter $(\kappa)$ using Eq. (1). This is essentially the interpolation method of Lythe et al. (2001) except that they carried out extensive filtering of the observational data.

\section{Interpolation skill}

Two measures of interpolation skill were investigated. First, the ability to reproduce observed thicknesses when data around the test point are excluded over progressively larger radii to simulate data sparsity (see summary in Table 1), 
Table 1. Skill of the methods. The slope and intercept of the linear fit of estimated ice thickness as a function of observed ice thickness averaged over exclusion radii of $5-150 \mathrm{~km}$ as detailed in Sect. 3 .

\begin{tabular}{l|c|cc|cc}
\hline Scheme & \# points & inverse distance cube & \multicolumn{2}{|c}{ flux method } \\
slope & $\begin{array}{c}\text { intercept } \\
\text { slope }\end{array}$ & $\begin{array}{c}\text { intercept } \\
(\mathrm{m})\end{array}$ \\
\hline streamline & 339207 & 0.806 & 560 & 0.938 & 183 \\
pseudo thickness & 1251760 & 0.768 & 666 & 0.919 & 264 \\
\hline
\end{tabular}

secondly the ability to predict the ice thickness measurements both along the first season of ICECAP flight lines (see Figs. 4 and 5) and at points within large mega-scale ice thickness "roughness" regions (see Table 2). Mega-scale ice thickness "roughness" is herein defined as the difference between the maximum and minimum smoothed ice thickness (see below for details on the smoothing) within a $50 \mathrm{~km}$ radius. The first of these tests also quantifies the robustness of the method.

The skill of the streamline interpolation method in estimating the ice thickness is evaluated against an IDC method similar to Lythe et al. (2001), where in the latter method the two nearest neighbors in each octant are used to remove directional biases. For this evaluation of skill, ICECAP season one ice thickness data from the flight lines were mapped onto a $1 \mathrm{~km} \times 1 \mathrm{~km}$ grid. For both the streamline and IDC methods, each gridded data point (test point) was considered in turn. All data points within a particular (variable) cut-off distance from the test point where temporarily discarded (reinstated for the next test point) from the data-set. The ice thickness at the test point was then estimated from this sub-sampled data-set using each method and the resulting thicknesses compared to the observed ice thickness. A least squares fit of the estimated ice thickness as a function of the observed ice thickness was calculated (see Table 3). Ideally, such a least squares data fit would have a slope of one and an intercept of zero. The two methods have similar skill at a $5 \mathrm{~km}$ data cut-off, but the IDC method quickly loses skill with increasing cut-off distance and levels out at a cut-off distance of around $130 \mathrm{~km}$. In contrast, the streamline method has a fairly constant skill regardless of the cut-off distance, i.e. is significantly more robust than the IDC method. In general, an inverse distance type method will tend to cluster the ice thicknesses around the average ice thickness, resulting in an overestimating the thickness of shallow ice and underestimating the thickness of deep ice (Fig. 6). When considering the ice thickness estimates as a function of the observed ice thickness, this behavior corresponds to a least squares slope less than one and a positive intercept, as shown in Table 3. The skill of the pseudo thickness method was evaluated in a similar manner. In this case all data points with $F(x, y)>600 \mathrm{~m}^{2} \mathrm{yr}^{-1}$ and $t(x, y) \leq 6000 \mathrm{~m}$ (78 235 points) were used to compare the observed and estimated ice thick- nesses. Again, points were excluded from the fitting data if they were within a variable cut-off distance, and Table 4 summarises the skill of this method compared to an IDC method.

Compared to an IDC method, the scheme presented in Sect. 2.2 has markedly reduced biases and is very robust, with the biases increasing only slowly for progressively larger data exclusion zones. Additionally, an inversedistance method shows a rapid fall in the correlation between the predicted and measured ice thicknesses in regions with large (greater than $1600 \mathrm{~m}$ ) mega-scale ice thickness "roughness" (Table 2), while the new scheme shows only slight degradation in skill. Furthermore, the scatter of the calculated ice thicknesses is greatly reduced compared to the IDC scheme, especially in data sparse regions (see Fig. 5). This is demonstrated by the greatly reduced inter-quartile distances (IQD) for TELVIS in Fig. 5) (especially in the mid range thicknesses where IDC methods cluster the calculated ice thicknesses). The increased number of outliers (1.5-3.0 IQD from the median) and extreme values (>3.0 IQD from the median) is still small for TELVIS $(0.3 \%$ and $1.7 \%$, respectively) and is a function of the TELVIS algorithms ability to deepen thicknesses beyond the local measurements (if the flux and slope indicate that this is appropriate) rather then revert towards a mean value. These outlier and extreme values are eliminated by the Gaussian smoothing discussed below.

The interpolation scheme is directionally biased to streamlines, and the unsmoothed interpolated ice thickness data shows high frequency variability normal to the streamlines, however the unsmoothed ice thickness data shows little spatial anisotropy. This high frequency noise normal to the streamlines is an artifact of the individual streamlines used in the interpolation, and does not represent physical structure so the interpolated ice thickness data-set was smoothed using a Gaussian filter with an e-folding scale of $10 \mathrm{~km}$ and is shown in Fig. 7a. This smoothing scale was chosen somewhat arbitrarily as a compromise between retaining excessive high frequency variance normal to streamlines and excessive smoothing.

\section{Discussion and conclusion}

The ice thickness reconstruction from the TELVIS interpolation scheme introduced here is shown in Fig. 7a. The flight track lines show differences between the TELVIS and ICECAP observed ice thicknesses (which did not inform TELVIS). These errors are consistently small, except for isolated regions near rapid thickness changes and far removed from constraining ice thicknesses observations (see Fig. 1). The ice thickness distribution reveals a widespread region of very thick ice (in excess of $3 \mathrm{~km}$ ), which is more extensive than is apparent in the BEDMAP compilation (Lythe et al., 2001). This thick ice extends towards the coast in the Denman Glacier trough. The thickest ice in the region is located 

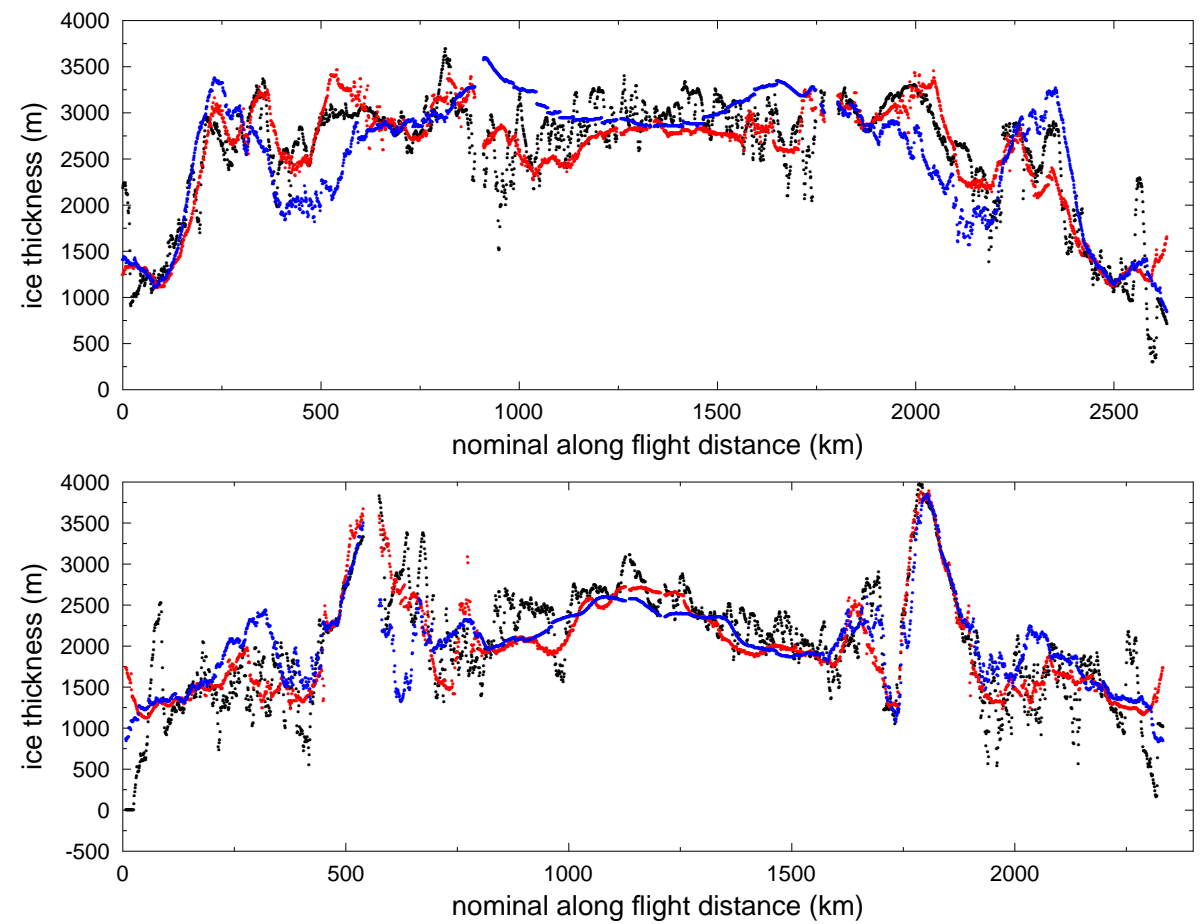

Fig. 4. Comparison between ICECAP ice thickness measurements (black) and predicted ice thicknesses along flight lines R19 (top) and R21 (bottom) from the historical data (Fig. 1a) TELVIS (red) and an inverse-distance-cubed scheme (blue). R19 and R21 are the second most westerly and most westerly pair, respectively, of flight lines shown on Fig. 7a.
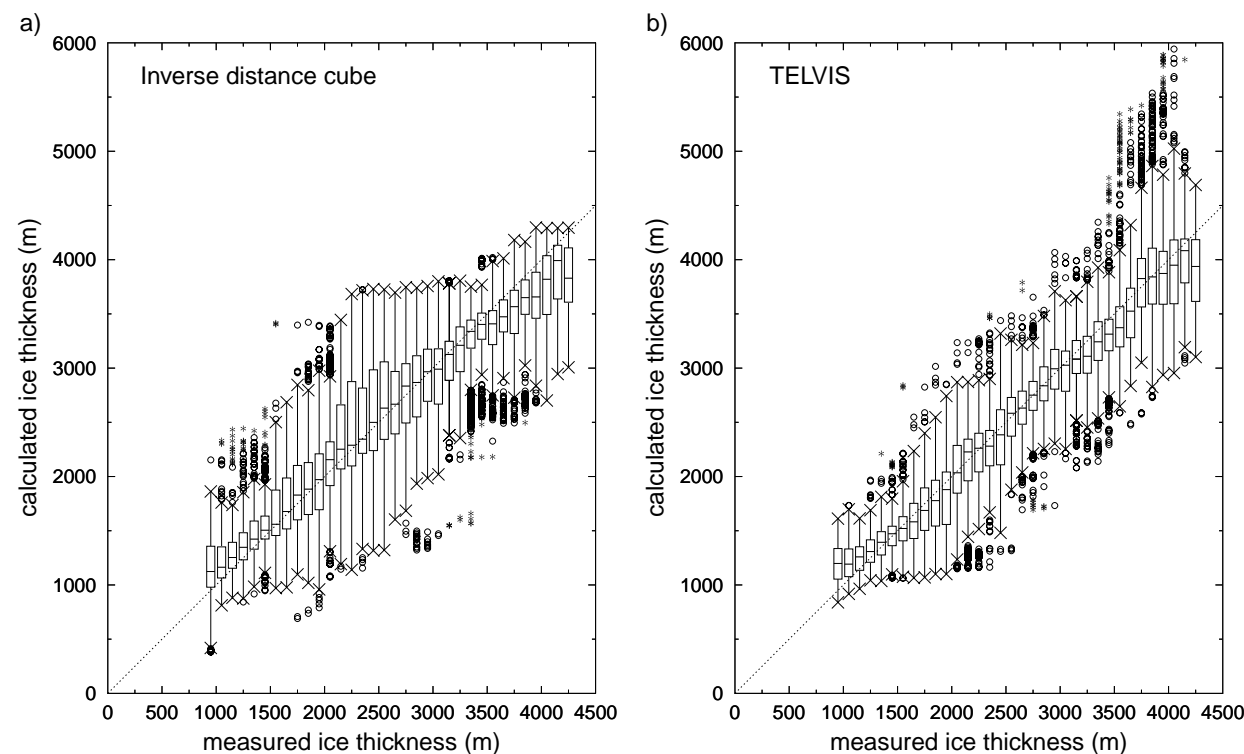

Fig. 5. Comparison between ICECAP ice thickness measurements and calculated ice thicknesses for the sparse data region of ICECAP flights to the west of Casey Station in $100 \mathrm{~m}$ bins based on measured ice thickness. (a) inverse distance cube and (b) TELVIS. Boxes show 25th percentile, median and 75th percentile, crosses show data points furthest from median but still within \pm 1.5 inter-quartile distances (IQD)(75th percentile-25th percentile) of the median, circles show data between 1.5 and 3.0 IQD of the median (outliers) and asterisk show data beyond 3 IQD of the median (extreme values). Dashed line shows ideal relationship. 
Table 2. Difference between (and correlation with) the ICECAP measured ice thicknesses and the estimated ice thicknesses as a function of mega-scale ice thickness "roughness" using only historical data-sets. $r$ is the Pearson's correlation coefficient and mega-scale ice thickness "roughness" is the difference between the maximum and minimum smoothed ice thickness within a $50 \mathrm{~km}$ radius.

\begin{tabular}{|c|c|c|c|c|c|c|c|}
\hline \multirow{2}{*}{$\begin{array}{c}\text { mega-scale ice } \\
\text { thickness "roughness" } \\
(\mathrm{m})\end{array}$} & \multirow[b]{2}{*}{ \# samples } & \multicolumn{3}{|c|}{ inverse distance cube } & \multicolumn{3}{|c|}{ TELVIS } \\
\hline & & $\begin{array}{r}\text { mean } \\
(\mathrm{m})\end{array}$ & $\begin{array}{l}\text { RMS } \\
(\mathrm{m})\end{array}$ & $\begin{array}{c}\text { Correlation } \\
r\end{array}$ & $\begin{array}{r}\text { mean } \\
(\mathrm{m})\end{array}$ & $\begin{array}{l}\text { RMS } \\
(\mathrm{m})\end{array}$ & $\begin{array}{c}\text { Correlation } \\
r\end{array}$ \\
\hline $200-299 . \overline{9}$ & 647 & 25.0 & 149 & 0.964 & 3.5 & 171 & 0.948 \\
\hline $300-399 . \overline{9}$ & 2977 & 69.2 & 185 & 0.908 & 88.1 & 229 & 0.869 \\
\hline $400-499 . \overline{9}$ & 6255 & 28.0 & 258 & 0.930 & 31.1 & 268 & 0.924 \\
\hline $500-599 . \overline{9}$ & 6217 & 8.7 & 273 & 0.892 & 65.0 & 266 & 0.902 \\
\hline $600-699 . \overline{9}$ & 5861 & 9.1 & 316 & 0.878 & 84.6 & 300 & 0.901 \\
\hline $700-799 . \overline{9}$ & 5163 & 22.0 & 351 & 0.865 & 70.7 & 308 & 0.903 \\
\hline $800-899 . \overline{9}$ & 6699 & -37.4 & 353 & 0.893 & 38.2 & 311 & 0.916 \\
\hline 900-999. & 5857 & -48.7 & 357 & 0.916 & 32.1 & 298 & 0.941 \\
\hline $1000-1099 . \overline{9}$ & 5447 & -44.0 & 393 & 0.918 & 31.6 & 320 & 0.946 \\
\hline $1100-1199 . \overline{9}$ & 3895 & -55.1 & 389 & 0.908 & -1.8 & 311 & 0.941 \\
\hline $1200-1299 . \overline{9}$ & 2841 & -26.9 & 350 & 0.923 & 21.3 & 336 & 0.929 \\
\hline $1300-1399 . \overline{9}$ & 3543 & 13.2 & 307 & 0.954 & -22.5 & 331 & 0.948 \\
\hline $1400-1499 . \overline{9}$ & 2023 & 42.1 & 316 & 0.966 & -13.5 & 318 & 0.965 \\
\hline $1500-1599 . \overline{9}$ & 2706 & 125 & 421 & 0.955 & -165 & 564 & 0.917 \\
\hline $1600-1699 . \overline{9}$ & 941 & 88.8 & 411 & 0.890 & 116 & 349 & 0.924 \\
\hline $1700-1799 . \overline{9}$ & 869 & 143 & 398 & 0.818 & 157 & 332 & 0.902 \\
\hline $1800-1899 . \overline{9}$ & 851 & 56.8 & 374 & 0.855 & 86.8 & 330 & 0.899 \\
\hline $1900-1999 . \overline{9}$ & 547 & 230 & 501 & 0.784 & 172 & 455 & 0.830 \\
\hline $2000-2099 . \overline{9}$ & 953 & 283 & 595 & 0.690 & -48.4 & 506 & 0.819 \\
\hline $2100-2199 . \overline{9}$ & 977 & -61.3 & 444 & 0.768 & -102 & 527 & 0.851 \\
\hline $2200-2299 . \overline{9}$ & 499 & 214 & 819 & 0.408 & 29.6 & 526 & 0.843 \\
\hline $2300-2399 . \overline{9}$ & 485 & 298 & 654 & 0.718 & -117 & 472 & 0.855 \\
\hline $2400-2499 . \overline{9}$ & 633 & 164 & 665 & 0.288 & 136 & 429 & 0.783 \\
\hline $2500-2599 . \overline{9}$ & 311 & -23.3 & 714 & 0.301 & 280 & 577 & 0.855 \\
\hline
\end{tabular}
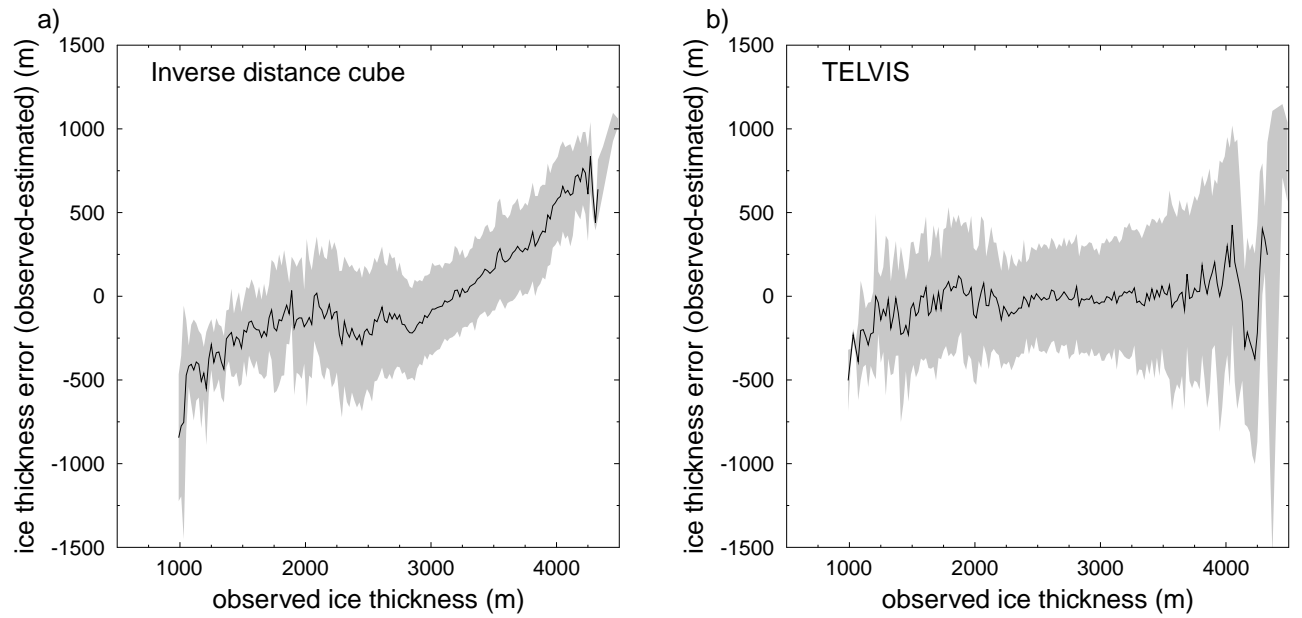

Fig. 6. Bias in ice thickness estimation, mean error (line) and standard deviation (shading) with a 90 km data exclusion zone, as a function of observed ice thickness for season one ICECAP data using (a) inverse distance cube and (b) TELVIS schemes. An ideal method would have a bias of zero across all depth scales, as approximated by the streamline method. The inverse-distance-cube method, in contrast, shows significant bias at both shallow and deep scales, as expected (see Sect. 3 for details). 

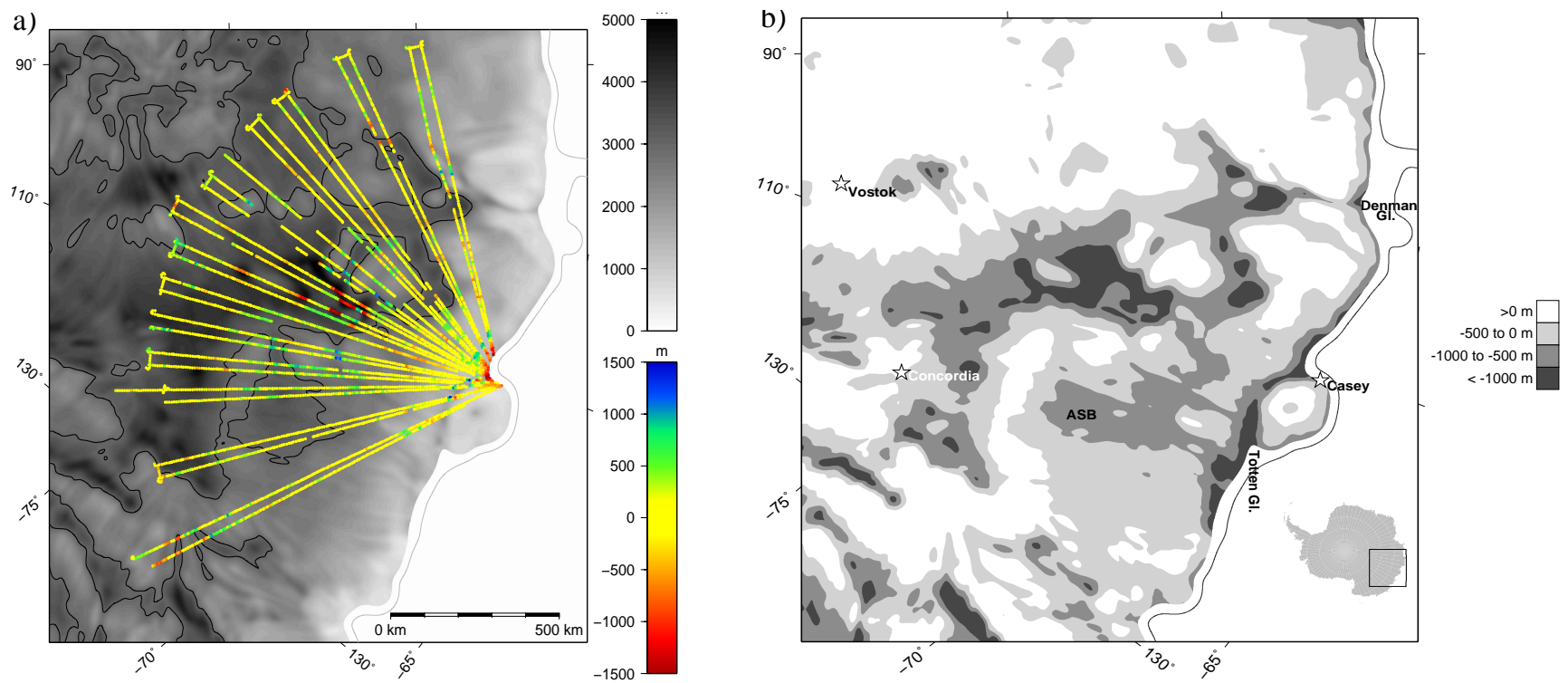

Fig. 7. (a) Smoothed TELVIS ice thickness interpolated onto a $1 \mathrm{~km} \times 1 \mathrm{~km}$ grid (gray scale), $3000 \mathrm{~m}$ thickness contour (black) shown for reference and thickness anomaly (measured minus calculated) along ICECAP season 1 flights (color scale). (b) Ice sheet bed elevation calculated from smoothed TELVIS ice thicknesses and a modified (see text) version of the Bamber et al. (2009) DEM.

Table 3. Skill and robustness of the streamline interpolation method. The slope and intercept of the linear fit of estimated ice thickness as a function of observed ice thickness is given as a function of the distance to the nearest data point. $r^{2}$ is the square of Pearson's correlation coefficient.

\begin{tabular}{l|c|ccc|crc}
\hline $\begin{array}{l}\text { cut-off } \\
\text { distance } \\
(\mathrm{km})\end{array}$ & $\begin{array}{c}\# \\
\text { points }\end{array}$ & \multicolumn{2}{|c|}{ inverse distance cube } & \multicolumn{3}{|c}{ streamline method } \\
intercept & $\begin{array}{c}r^{2} \\
(\mathrm{~m})\end{array}$ & $\begin{array}{r}\text { slope } \\
\text { intercept }\end{array}$ & $r^{2}$ \\
\hline 5 & 40863 & 0.959 & 117 & 96 & 0.944 & 165 & 89 \\
10 & 35966 & 0.931 & 201 & 93 & 0.939 & 181 & 86 \\
20 & 31234 & 0.884 & 339 & 89 & 0.928 & 218 & 82 \\
30 & 28673 & 0.853 & 428 & 85 & 0.918 & 247 & 77 \\
40 & 25217 & 0.819 & 530 & 82 & 0.911 & 272 & 73 \\
50 & 23040 & 0.770 & 672 & 78 & 0.893 & 320 & 69 \\
60 & 21362 & 0.741 & 755 & 75 & 0.893 & 312 & 67 \\
70 & 20086 & 0.697 & 882 & 72 & 0.909 & 269 & 68 \\
80 & 18722 & 0.674 & 955 & 69 & 0.936 & 192 & 69 \\
90 & 17008 & 0.668 & 973 & 67 & 0.964 & 116 & 69 \\
100 & 15613 & 0.648 & 1030 & 62 & 0.970 & 89 & 67 \\
110 & 14297 & 0.641 & 1057 & 59 & 1.000 & 1 & 64 \\
120 & 13066 & 0.621 & 1124 & 55 & 1.000 & -11 & 62 \\
130 & 12194 & 0.619 & 1131 & 51 & 1.001 & -24 & 60 \\
140 & 11312 & 0.632 & 1084 & 51 & 1.002 & -33 & 59 \\
150 & 10553 & 0.648 & 1024 & 52 & 1.064 & -241 & 59 \\
$5-150$ & 339207 & 0.806 & 560 & 80 & 0.938 & 183 & 74 \\
\hline
\end{tabular}

in the Aurora Subglacial Basin almost due south of Casey Station.

The thickness reconstruction shown in Fig. 7a may be used in conjunction with a digital elevation model to derive an ice sheet basal elevation map, as shown in Fig. 7b. Here the computed ice thickness has been subtracted from the smoothed DEM used in the flux calculation. This reconstruction method can be applied to other icecaps and requires only a good quality digital elevation model, an estimate of surface mass balance and at least sparse ice thickness measurements. The method has only a small sensitivity to the accumulation distribution, arising from the 1/5 exponent in Eq. (1), and the local normalisation of $\kappa$, which assimilates local variations. The skill of the interpolation scheme has been tested by comparing Fig. $7 \mathrm{~b}$ with a similar map produced with inclusion of ICECAP interim ice thickness measurements (not shown). Except for excessive deepening around the fringes of Lake Vostok, the deep section of the Aurora Subglacial Basin and along the Denman Glacier outflow, they show remarkable agreement considering the sparsity of the data set used. The mean difference between computed ice sheet basal elevations is $35.4 \mathrm{~m}$ with an RMS difference of $178 \mathrm{~m}$ after smoothing (or for unsmoothed data, mean $40.9 \mathrm{~m}$ and RMS $265 \mathrm{~m})$.

We are not aware of any previous formal definition of the Aurora Subglacial Basin, so based on the broad-scale topography we propose defining the "Aurora Subglacial Basin" as the contiguous region at or below $500 \mathrm{mb}$ b.s.l., including the Totten Glacier and the "deep Aurora Subglacial Basin" as the sub-region deeper than $1000 \mathrm{~m}$ b.s.l. A number of key features emerge from this new ice sheet basal elevation reconstruction when compared to the BEDMAP bedrock product (Lythe et al., 2001). Over the area shown in Fig. 7b the new reconstruction shows an ice sheet with a more extensive submarine base $\left(1.33 \times 10^{6} \mathrm{~km}^{2}\right.$ compared to 
Table 4. Skill and robustness of the pseudo thickness weighted method. The slope and intercept of the linear fit of estimated ice thickness as a function of observed ice thickness is given as a function of the distance to the nearest data point. $r^{2}$ is the square of Pearson's correlation coefficient.

\begin{tabular}{l|ccc|ccc}
\hline $\begin{array}{l}\text { cut-off } \\
\text { distance } \\
(\mathrm{km})\end{array}$ & \multicolumn{2}{|c|}{ inverse distance cube } & \multicolumn{3}{|c}{ pseudo thickness method } \\
slope & intercept & $r^{2}$ & slope & intercept & $r^{2}$ \\
$(\mathrm{~m})$ & $(\%)$ & & $(\mathrm{m})$ & $(\%)$ \\
\hline 5 & 0.962 & 109 & 96 & 0.945 & 162 & 95 \\
10 & 0.937 & 182 & 94 & 0.931 & 204 & 93 \\
20 & 0.895 & 304 & 90 & 0.914 & 256 & 90 \\
30 & 0.864 & 396 & 87 & 0.904 & 294 & 88 \\
40 & 0.839 & 471 & 85 & 0.903 & 301 & 86 \\
50 & 0.810 & 555 & 82 & 0.904 & 304 & 84 \\
60 & 0.789 & 614 & 81 & 0.906 & 302 & 83 \\
70 & 0.764 & 683 & 78 & 0.905 & 307 & 82 \\
80 & 0.744 & 736 & 77 & 0.909 & 297 & 82 \\
90 & 0.729 & 775 & 76 & 0.916 & 279 & 81 \\
100 & 0.703 & 846 & 73 & 0.920 & 270 & 80 \\
110 & 0.686 & 892 & 72 & 0.928 & 251 & 80 \\
120 & 0.670 & 936 & 71 & 0.931 & 242 & 78 \\
130 & 0.646 & 1002 & 69 & 0.932 & 242 & 78 \\
140 & 0.627 & 1057 & 67 & 0.930 & 249 & 77 \\
150 & 0.616 & 1092 & 67 & 0.931 & 244 & 76 \\
$5-150$ & 0.768 & 666 & 79 & 0.919 & 263 & 83 \\
\hline
\end{tabular}

$1.21 \times 10^{6} \mathrm{~km}^{2}$ below sea-level). Additionally, the TELVIS reconstruction has a more extensive Aurora Subglacial Basin $\left(3.56 \times 10^{5} \mathrm{~km}^{2}\right.$ compared to $\left.8.97 \times 10^{4} \mathrm{~km}^{2}\right)$ and deep $\mathrm{Au}$ rora Subglacial Basin $\left(7.53 \times 10^{4} \mathrm{~km}^{2}\right.$ compared to $1.75 \times$ $10^{2} \mathrm{~km}^{2}$ ). Alternatively $21 \%$ of the Aurora Subglacial Basin is below $1000 \mathrm{~m}$ b.s.l. in the new reconstruction compared to a mere $0.2 \%$ in BEDMAP. There are also deeper and more extensive submarine connections from the deep interior to the coastal grounding zone. The average base is deeper (65 m b.s.l. vs. $35 \mathrm{~m}$ b.s.l.) than BEDMAP, especially west of Law Dome, where the data are sparsest. The overall basal topography reflects the drainage through the Totten and Denman glaciers. The broad morphology of the Aurora Subglacial Basin shows a basin largely at depths greater than 500 m.b.s.l. inland of Law Dome, extending to around $75^{\circ} \mathrm{S}$ latitude and from $100^{\circ} \mathrm{E}$ to $120^{\circ} \mathrm{E}$. The Aurora Subglacial Basin is bounded on the coastal side with a sill that only rises above sea-level on the Knox Coast, west of Law Dome toward the Denman outlet. This sill is cut with deep connections (deeper than $500 \mathrm{~m}$ b.s.l. at the Totten and Denman trunks) revealing a potential for a marine ice sheet instability (Weertman, 1974). This potential, together with the observed surface lowering in the Totten and Denman outlet (Pritchard et al., 2009), underscores the importance of developing ice sheet modeling based on the detailed basal boundary conditions for this region. Specific aspects of the under ice topography are addressed in separate publications, for example the glacial evolution is reported in Young et al. (2011), while the basal hydrology of the region is discussed in Wright et al. (2011).

\section{Appendix A}

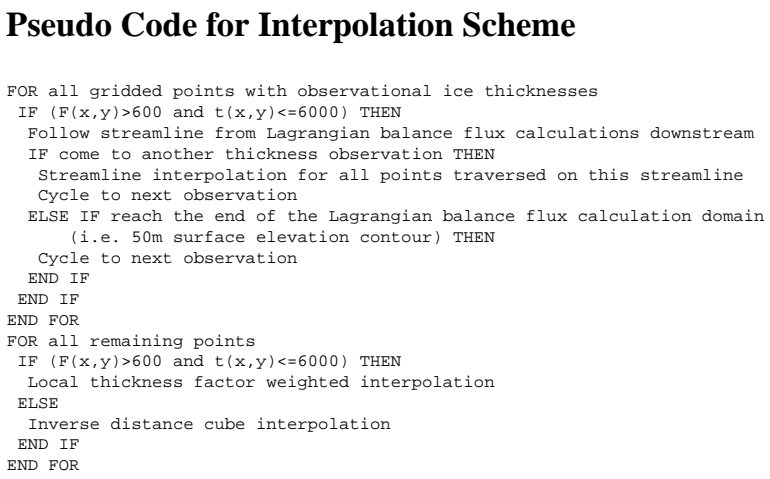

Acknowledgements. Funding for this work was provided by the UK Natural Environment Research Council grant NE/D003733/1, NSF grant ANT-0733025, the Jackson School of Geosciences and the G. Unger Vetlesen Foundation. The Australian Antarctic Division provided funding and logistical support (ASAC 3103). This work was supported by the Australian Government's Cooperative Research Centres Programme through the Antarctic Climate and Ecosystems Cooperative Research Centre (ACE CRC). J. Bamber, E. Waddington, C. Ritz and several anonymous reviewers provided very constructive reviews of the manuscript.

Edited by: J. L. Bamber

\section{References}

Allison, I., Alley, R. B., Fricker, H. A., Thomas, R. H., and Warner, R.: Ice sheet mass balance and sea level, Antarct. Sci., 21, 413426, doi:10.1017/S0954102009990137, 2009.

Bamber, J. L., Gomez-Dans, J. L., and Griggs, J. A.: A new 1 km digital elevation model of the Antarctic derived from combined satellite radar and laser data - Part 1: Data and methods, The Cryosphere, 3, 101-111, doi:10.5194/tc-3-101-2009, 2009.

Blankenship, D., Morse, D.,Finn, C., Bell, R., Peters, M., Kempf, S., Hodge, S., Studinger, M., Behrendt, J., and Brozena, J.: Geological controls on the initiation of rapid basal motion for West Antarctic Ice Streams: A geophysical perspective including new airborne radar sounding and laser altimetry results, in: The West Antarctic Ice Sheet: Behavior and Environment, Antarctic Research Series, edited by: Alley, R. and Bindschadler, R., 77, 105121, American Geophysical Union, Washington, D.C., 2001.

Holt, J., Blankenship, D., Morse, D., Young, D., Peters, M., Kempf, S., Richter, T., Vaughan, D., and Corr, H.: New boundary conditions for the West Antarctic ice sheet: Subglacial topography of the Thwaites and Smith Glacier catchments, Geophys. Res. Lett., 33, L09502, doi:10.1029/2005GL025561, 2006.

Le Brocq, A., Payne, A., and Siegert, M.: West Antarctic balance calculations: Impact of flux-routing algorithm, smoothing algorithm and topography, Comput. Geosci., 32,, 1780-1795, 2006. 
Lythe, M. B., Vaughan, D. G., and the BEDMAP Consortium: BEDMAP: A new ice thickness and subglacial topographic model of Antarctica, J. Geophys. Res., 106, 11335-11351, 2001.

Mercer, J.: West Antarctic ice sheet and $\mathrm{CO}_{2}$ greenhouse effect: a threat of disaster, Nature, 271, 312-325, 1978.

Peters, M., Blankenship, D., and Morse, D.: Analysis techniques for coherent airborne radar sounding: Application to West Antarctic ice streams, J. Geophys. Res., 110, B06303, doi:10.1029/2004JB003222, 2005.

Pettit, E. and Waddington, E.: Ice flow at low deviatoric stress, J. Glaciol., 49, 359-369, 2003.

Pritchard, H., Arthern, R., Vaughan, D. G., and Edwards, L.: Extensive dynamic thinning on the margins of the Greenland and Antarctic ice sheets, Nature, 461, 971-975, doi:10.1038/nature08471, 2009.

Siegert, M.: Antarctic subglacial topography and ice sheet evolution, Earth Surf. Proc. Land., 33, 646-660, doi:10.1002/esp.1670, 2008.

Soille, P., Vogt., J., and Colombo, R.: Carving and adaptive drainage enforcement of grid digital elevation models, Water Resour. Res., 39(13), doi:10.1029/2002WR001879, 2003.

Testut, L., Hurd, R., Coleman, R., Frédérique, R., and Legrésy, B.: Comparison between computed balance velocities and GPS measurements in the Lambert Glacier basin, East Antarctica, Ann. Glaciol., 37, 337-343, 2003.

Thomas, R.: The dynamics of marine ice sheets, J. Glaciol., 24, 167-177, 1979 .

Urbini, S., Cafarella, L., Zirizzotti, A., Tabacco, I., Boltari, C., Baskaradas, J., and Young, N.: RES data analysis on the Shackleton Ice Shelf, Ann. Geophys-Italy, 53, 79-87, doi:10.4401/ag4563,2010 . van de Berg, W. J., van den Broeke, M. R., Reijmer, C. H., and van Meijgaard, E.: Reassessment of the Antarctic surface mass balance using calibrated ou tput of a regional atmospheric climate model, J. Geophys. Res., 111, doi:10.1029/2005JD006495, 2006.

Velicogna, I.: Increasing rates of ice mass loss from the Greenland and Antarctic ice sheets revealed by GRACE, Geophys. Res. Lett., 36, doi:10.1029/2009GL040222, 2009.

Warner, R. C. and Budd, W. F.: Derivation of ice thickness and bedrock topography in data-gap regions over Antarctica, Ann. Glaciol., 31, 191-197, 2000.

Weertman, J.: Stability of the junction of an ice sheet and an ice shelf, J. Glaciol., 13, 3-11, 1974.

Wright, A., Young, D., Roberts, J., Dowdeswell, J., Bamber, J., Young, N., LeBrocq, A., Warner, R., Payne, A., Blankenship, D., van Ommen, T., and Siegert, M.: Evidence for a hydrological connection between the ice divide and ice sheet margin in the Aurora Subglacial Basin sector of East Antarctica, submitted to J. Geophys. Res-Earth, 2011.

Young, D., Wright, A., Roberts, J., Warner, R., Young, N., Greenbaum, J., Schroeder, D., Holt, J., Sugden, D., Blankenship, D., van Ommen, T., and Siegert, M.: Ice-covered fjords indicate a dynamic East Antarctic Ice Sheet margin in the Aurora Subglacial Basin, Nature, 474, 72-75, doi:10.1038/nature10114, 2011.

Young, N., Goodwin, I., Hazelton, N., and Thwaites, R.: Measured velocities and ice flow in Wilkes Land, Antarctica, Ann. Glaciol., 12, 192-197, 1989a.

Young, N., Malcolm, P., Mantell, P., and McGibbon, E.: Velocity and surface-lowering measurements on Law Dome, Antarctica, Ann. Glaciol., 12, 220, 1989b. 